\title{
A new technique for nonsurgical embryo recovery in superovulated ewes treated with estradiol and oxytocin
}

\author{
O. I. Azawi \\ Coll. of Vet. Med./ Univ. of Mosul,
}

\section{Abstract}

The development of an efficient and practicable method for transcervical collection of embryos in Awassi ewes to the improvement of embryo recovery was investigated. Twentyfour non-pregnant Awassi ewes of 3-4 years of age were randomly allocated into two groups $(\mathrm{n}=12)$. Each ewe was treated with a progesterone impregnated intra-vaginal sponge for 12 days. The following superovulation treatment was used: ewes received $1200 \mathrm{IU}$ of eCG once as an intramuscular injection $48 \mathrm{~h}$ prior to sponge withdrawal. Ovarian response was assessed by determining the number of corpora lutea by laparoscopy at day 6 after mating. Ewes of group $1(\mathrm{n}=12)$ their embryos were recovered using semi-laparoscopic technique. Ewes of group $2(n=12)$ their embryos were recovered using transcervical technique. All ewes of this group on the evening of day 5 post inseminations, received an i.m. injection of estradiol $17 \beta 2$ $\mathrm{mg}, 12 \mathrm{~h}$ later, an i.v. injection of $10 \mathrm{IU}$ of oxytocin. A bovine teat dilator introduced into cervical canal and gradually dilated in order to dilate and open the cervical canal with a help of screw provided with the instrument. Results of the present study showed that there was no significant difference in the number of recovered embryos in superovulated ewes when animals treated with estradiol and oxytocin with transcervical technique and semilaparoscopic technique. It was possible to pass the catheter through the cervix by aid of bovine teat dilator enhanced by estradiol and oxytocin treatment. In conclusion, the technique for transcervical collection of embryo from ewes, as described in the present study, may give new encouragement to embryo transfer programs in this species.

Key words: Superovulation. Transcervical embryo recovery. semi-laparoscopic technique. Estradiol. Oxytocin. Awassi ewes.

\section{Introduction}

Surgical procedures of embryo recovery and transfer are limiting factors reducing the development and commercial utilization of embryo transfer in sheep production. Development of a suitable method for sheep embryo transfer is still in the experimental phase $(1,2)$. Unlike the cow, the cervix of the ewe is formidable barrier to penetrate for transcervical intrauterine insemination (3), embryo recovery or transfer not only due to small orifice and a narrow luminal diameter, but also due to its caudally facing, eccentric series of four to eight funnel like rings (4, 5). Transcervical embryo collection has always been hampered by the difficulty of introducing a catheter through the cervix, and the incapability of rectal manipulation of the tract.Sheep embryos are usually surgically recovered and surgery is carried out under general anesthesia (6).
Disadvantages of the surgical approach are the stress to the animal and adhesions forming that limit the number of times it can be applied to the same animals. Laparoscopic embryo collection results in fewer adhesions (7), but requires special equipment and highly trained personnel. Attempts are made for transcervical embryo recovery $(8,9)$ and after ripening the cervix by injecting hormones like $\mathrm{PGE}_{2}$ and estradiol (1), intravaginal application of $\mathrm{PGE}_{2}(2)$ or using estradiol and oxytocin $(10,11,12)$. Although, some successes have been achieved using cervical collection of embryos, more is necessary to make it a reliable option in sheep.The present study was directed at development of an efficient and practicable method for transcervical collection of embryos in Awassi ewes. 


\section{Materials and methods}

The experiment was conducted in the breeding season when major breeding activities (September 2007) commences at the College of Veterinary Medicine, University of Mosul farm. Twenty-four nonpregnant Awassi ewes of 3-4 years of age were randomly allocated in equal number $(\mathrm{n}=12)$ to two groups. None of the ewes included in this study had been previously subjected to hormonal treatments. Throughout the experimental period, the animals were kept in open front barrens, were fed individually with concentrated mixture (containing 65\% barley, $33 \%$ bran and $2 \%$ minerals and salt mixed in the farm) of $1 \mathrm{~kg}$ per ewe per day, and were given water ad libitum.

Estrous synchronization and Super ovulation treatment

Each ewe was treated with a progesterone impregnated intravaginal sponge (Synncropart $40 \mathrm{mg}$ sheep sponge, Ceva Sante Animale, France) for 12 days. The following superovulation treatment was used: ewes received $1200 \mathrm{IU}$ of eCG (Synncropart) once as an intramuscular injection $48 \mathrm{~h}$ prior to sponge withdrawal.

Oestrous detection and natural insemination

Oestrous in ewes was detected with the aid of aproned ram (ram: ewe $=1: 12$ ) of high sexual vigour at $6 \mathrm{~h}$ intervals. Ewes were mated naturally at least two times after oestrous detection with Awassi rams of proven fertility at $8 \mathrm{~h}$ intervals.

Superovulatory response

Ovarian response was assessed by determining number of corpora lutea by laparoscopy on day 6 after mating. Both ovaries were examined and the number of corpora lutea either normal $(>3 \mathrm{~mm})$ and anomalous $(\leq 3 \mathrm{~mm})$ and large unovulated follicles $(>4 \mathrm{~mm})$ were recorded. Ewes showing more than three corpora lutea were considered as superovulated.

\section{Embryo recovery}

Ewes of group $1(n=12)$ their embryos were recovered using semi-laparoscopic technique as described by Bari (13). Embryo recovery was performed by semilaparoscopic and by flushing both uterine horns. Food was withheld $24 \mathrm{~h}$ prior to surgery. All animals underwent sedation using xylazine $0.22 \mathrm{mg} / \mathrm{Kg} \quad \mathrm{BW}$ intravenously. A local anaesthesia at trocher and cannula entry sites was achieved by subcutaneous injection of 10 $\mathrm{ml} 2 \%$ lidocaine. The animals fixed on a movable surgical table in an upside-down position and underwent laparoscopy followed by shaving and disinfection of the abdomen. The abdomen was inflated with $\mathrm{CO}_{2}$ and laparoscopic cannula and laparoscope were placed into the abdomen. An additional cannula was also inserted for laparoscopic instruments. Each uterine horn was flushed by insertion of a needle, attached to a sterile syringe with flushing media (modified Dulbecco's phosphate buffered saline plus $1 \%$ bovine serum and the $\mathrm{PH}$ adjusted to 7.2-7.6 with osmotic pressure 270-310 mOs) near the uterotubal junction. Each uterine horn was flushed with $30 \mathrm{ml}$ flushing media, collected in Petri dishes through a Foley catheter inserted in the base of the uterine horns for recovery of the embryos. The collected flushing media was examined for the presence of oocytes and embryos under a stereo microscope.Ewes of group 2 ( $\mathrm{n}=$ 12) their embryos were recovered using transcervical technique. All ewes of this group on the evening of day 5 post inseminations, received an i.m. injection of estradiol $17 \beta 2 \mathrm{mg}, 12 \mathrm{~h}$ later, an i.v. injection of $10 \mathrm{IU}$ of oxytocin. Wool was shorn around the perineal area $2 \mathrm{~h}$ before treatment. The perineal area was scrubbed with an antiseptic soap and rinsed thoroughly. Excess water and antiseptic were removed with dry gauze sponges. Ewes were immobilized in a standing position. A lubricated speculum inserted into the vagina with the help of penlight and the external os of the cervix was grasped with the Allis forceps. The speculum was removed and the external os was carefully pulled caudally until it almost reached the vulva opening. A bovine teat dilator introduced into cervical canal and gradually dilated in order to dilate and open the cervical canal with a 
help of screw provided with the instrument. A three-way Foley catheter was introduced, and gentile probing and twisting motion passed the cervical canal with the aid of a stylet. Once the catheter was introduced into the desired uterine body, the stylet was removed. The flushing medium was infused into the uterus by force of gravity by lifting the infusion flask $150 \mathrm{ml}$ above the back of the ewe. After infusion of $50 \mathrm{ml}$, the infusion tube was closed, and the effluent was collected in a $50 \mathrm{ml}$ test tube. The procedure was repeated six times and then the catheter

\section{Results}

Table 1 presents the superovulation response of ewes treated with eCG through number of corpora lutea and recovered embryos using semi-laparoscopic technique and transcervical technique. There was no significant difference in the number of recovered embryos in superovulated ewes when animals were treated with estradiol and oxytocin with transcervical technique and semilaparoscopic technique. However, the two techniques used in the present study for embryo recovery indicate no effect of these techniques on embryos based on morphological examination. Ewes received estradiol and oxytocin showed deepest

\section{Discussion}

This is the first report that describes using bovine teat dilator for dilating the cervix in ewes and facilitating the passage of the Foley catheter through the ewe cervix for successful embryo recovery. Among the protocols assessed, there was no significant difference in embryo recovery rates achieved using semilaparoscopic technique and transcervical technique. This result indicates that using transcervical technique with the aid of bovine teat dilator enhanced by estradiol and oxytocin treatment was possible to pass the catheter through the ewe cervix for successful embryo recovery. The disadvantages of surgical approach including adhesions (14), general anesthesia (6), requirement of a special equipments, and highly trained personnel (13) using semi-laparoscopic technique can was gently removed. The removed fluid was emptied into large Petri dishes that were covered and kept at $38^{\circ} \mathrm{C}$ on a warm stage. The embryos were identified under a stereo microscope.

Statistical analysis

The student $t$ test was used to evaluate the differences in superovulation response in number of corpora lutea and recovery rate between means of the groups of the same parameter using the software Sigma stat (SIGMA STAT, Jandel scientific software V3.1 Inc., Richmond, CA, USA, 2004).

cervical penetration. The bovine teat dilator used for cervical dilatation was passed into the cervical canal in less than one minute. Only one ewe was affected with chronic cervicitis with enlarged fibrotic cervix showed difficulty in passing the teat dilator and takes between 5-7 minutes to pass the cervical canal with slight bleeding during rotation and forced passing of the bovine teat dilator. It was possible to pass the catheter through the cervix by aid of bovine teat dilator enhanced by estradiol and oxytocin treatment. An average of $85 \%$ of the medium infused in the uterus by transcervical technique was recovered.

be avoided using this technique. Stellflug (12) have reported acceptable embryo recovery using estradiol and oxytocin treatment to facilitate the passage of a catheter through the ewe cervix. In addition, Wulster-Radcliffe (7) demonstrated that embryo from superovulated could be recovered using transcervical technique. In the present study, we obtained higher rates of embryo recovery using transcervical technique with the aid of hormonal treatment and bovine teat dilator compared these studies. There are several methods for crossing the cervix in ewe. Physical methods: attaching a haemostatic forceps to the external cervical os and retracting the cervix to align the cervical os with the opening of the rings and decrease obstructions to the uterine lumen $(3,4)$. 
These methods are traumatic (15) and their use is limited. Chemical methods: by dilating the cervix with different hormones (estradiol, oxytocin, PGE2) had been used previously with limited success (8). The value of oxytocin is as cervical dilator to relax the cervix and improve cervical penetration but cervical traumas are still evident (11). Because of the difficulty in crossing the cervix by physical or hormonal methods, we design a method of using equipment (bovine teat dilator) which adapts to the anatomy of the cervix with the combination of physical and chemical methods and could be an efficient way of achieving enlargement and relaxation cervical canal as desired for

Table 1. Numbers of corpora lutea, recovered embryos using Semi-laparoscopic technique and transcervical technique for embryo recovery in Awassi ewes superovulated with eCG.

\begin{tabular}{|c|c|c|c|}
\hline $\begin{array}{c}\text { Types of embryo } \\
\text { recovery }\end{array}$ & No. of corpora lutea & $\begin{array}{c}\text { No. of recovered } \\
\text { embryos }\end{array}$ & $\begin{array}{l}\text { Recovered embryos } \\
(\%)\end{array}$ \\
\hline $\begin{array}{c}\text { Semi-laparoscopic } \\
\text { technique }(\mathrm{n}=12)\end{array}$ & $5.83 \pm 0.54$ & $4.44 \pm 0.66$ & 76.2 \\
\hline $\begin{array}{c}\text { Transcervical } \\
\text { technique }(\mathrm{n}=12)\end{array}$ & $5.39 \pm 0.39$ & $4.06 \pm 0.74$ & 75.3 \\
\hline
\end{tabular}

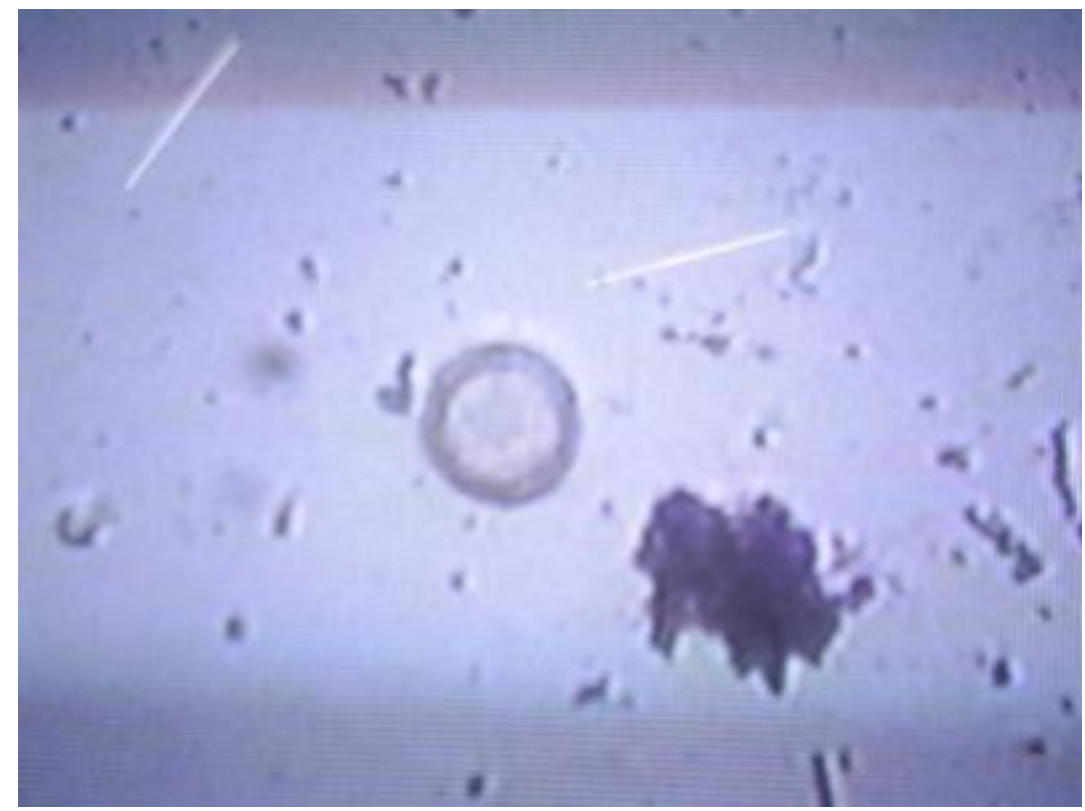

Fig. 1. Unfertilized ovum X400. 


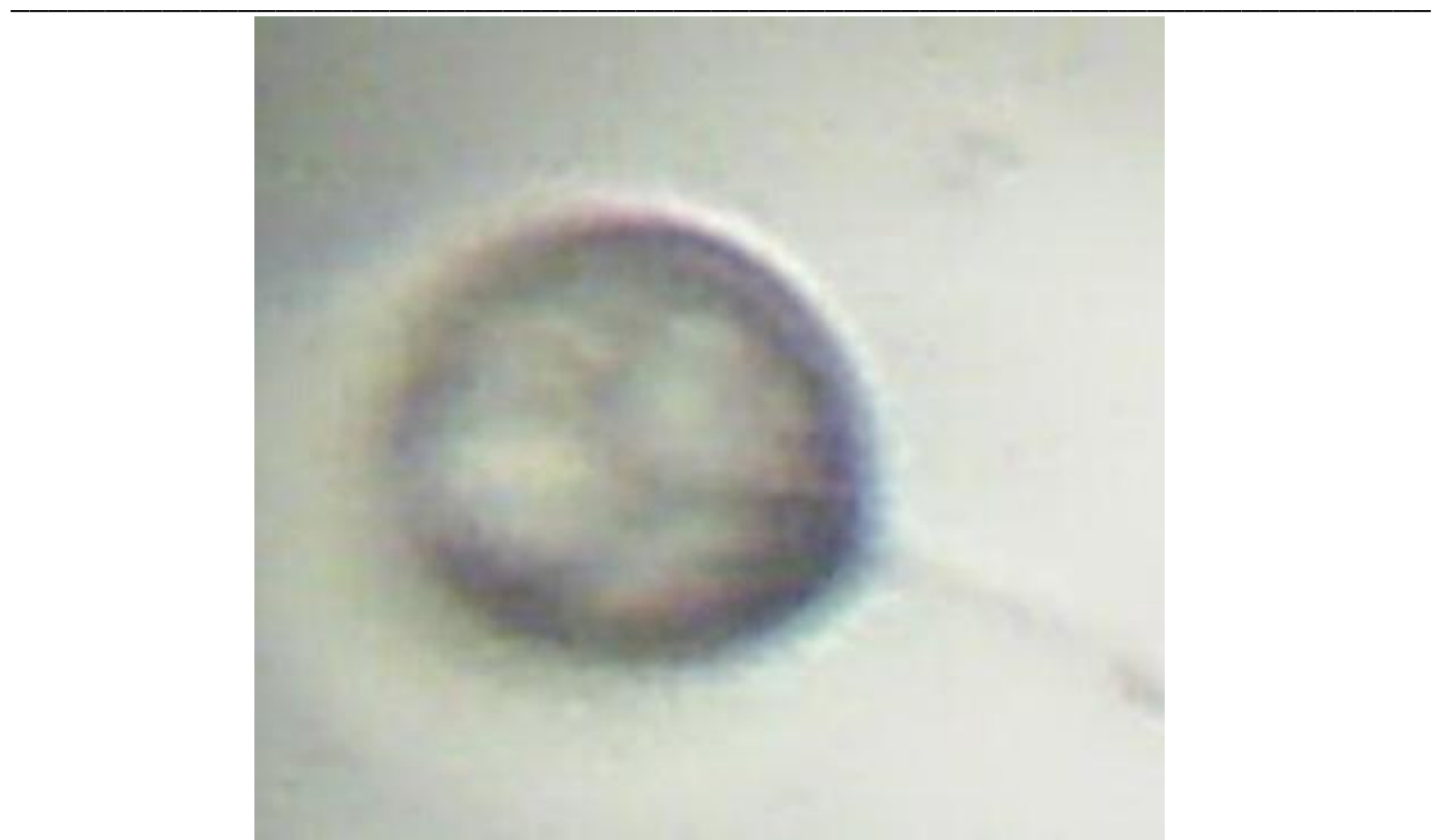

Fig. 2. Recovered embryo with four cells X400.

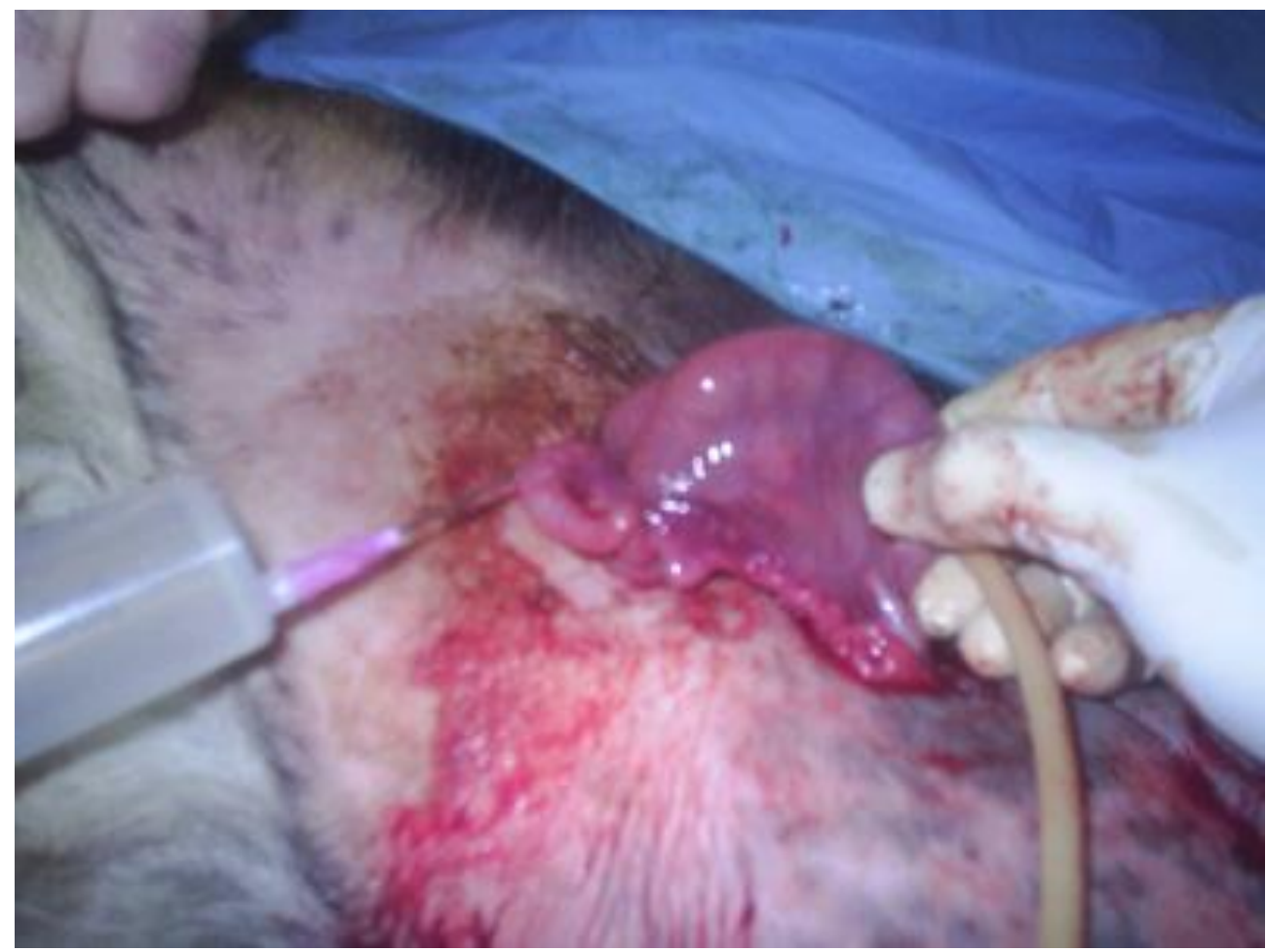

Fig. 3. Embryos were recovered using semi-laparoscopic technique in ewes. 


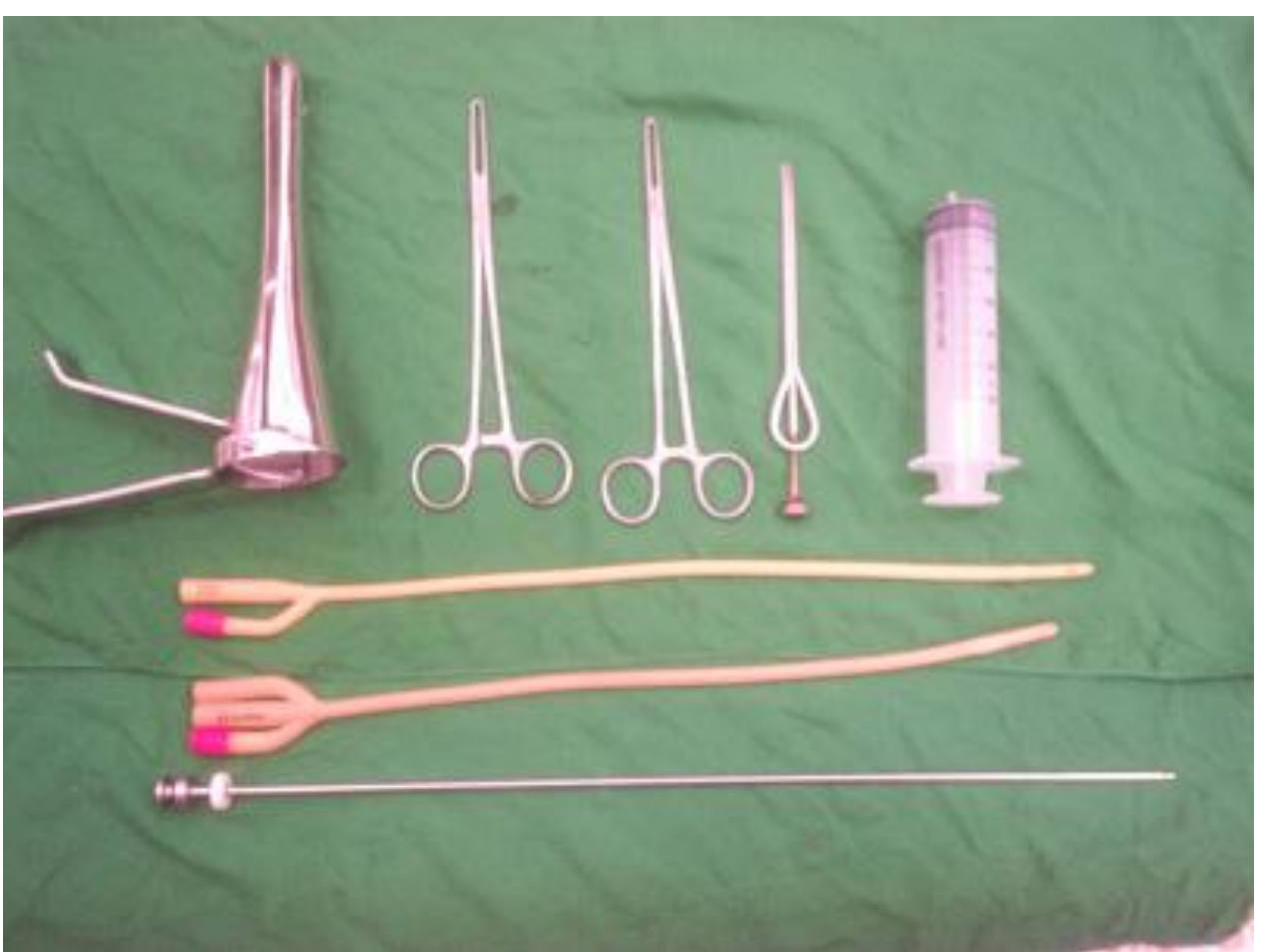

Fig. 4. Instruments used for transcervical technique of embryo recovery in ewes.
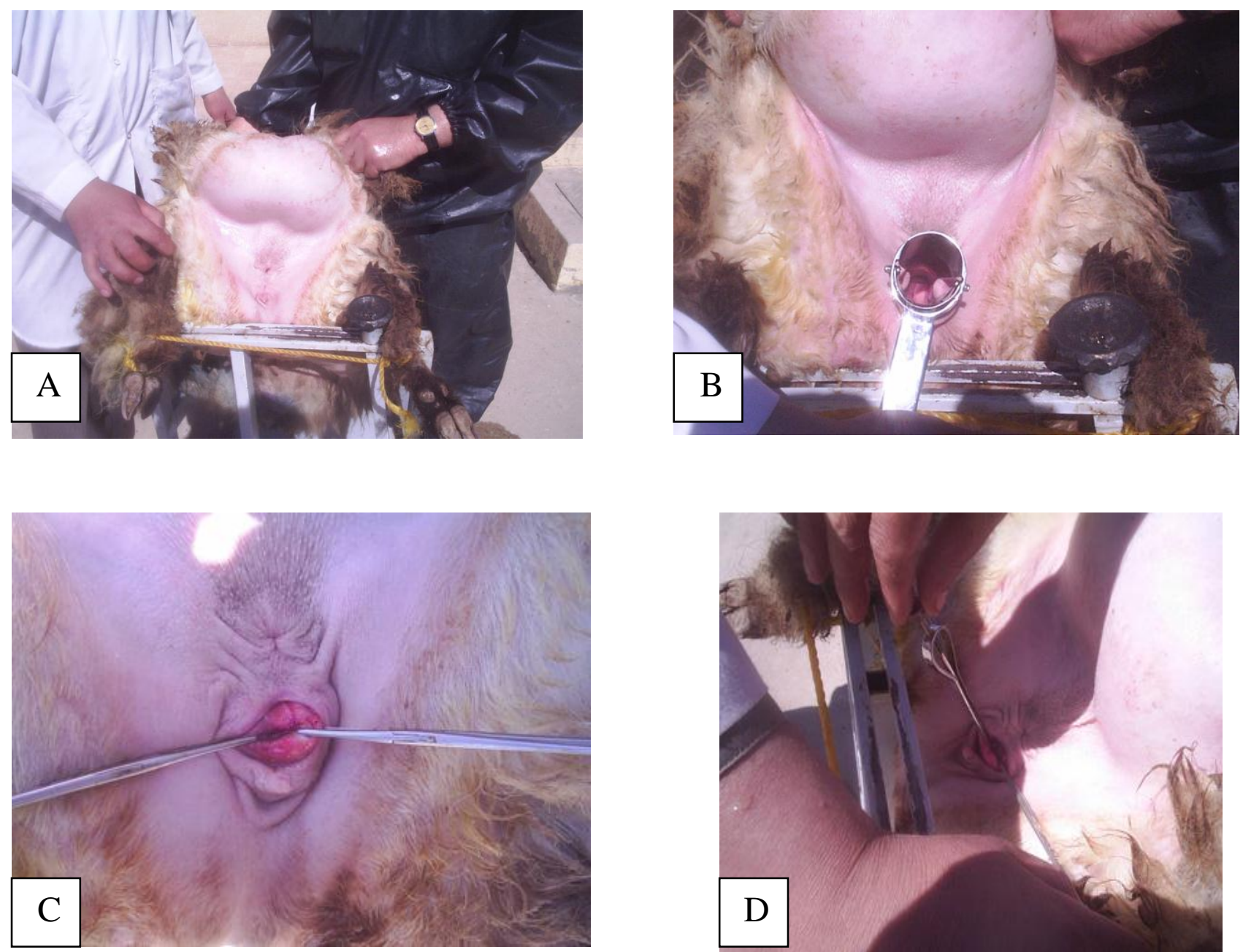


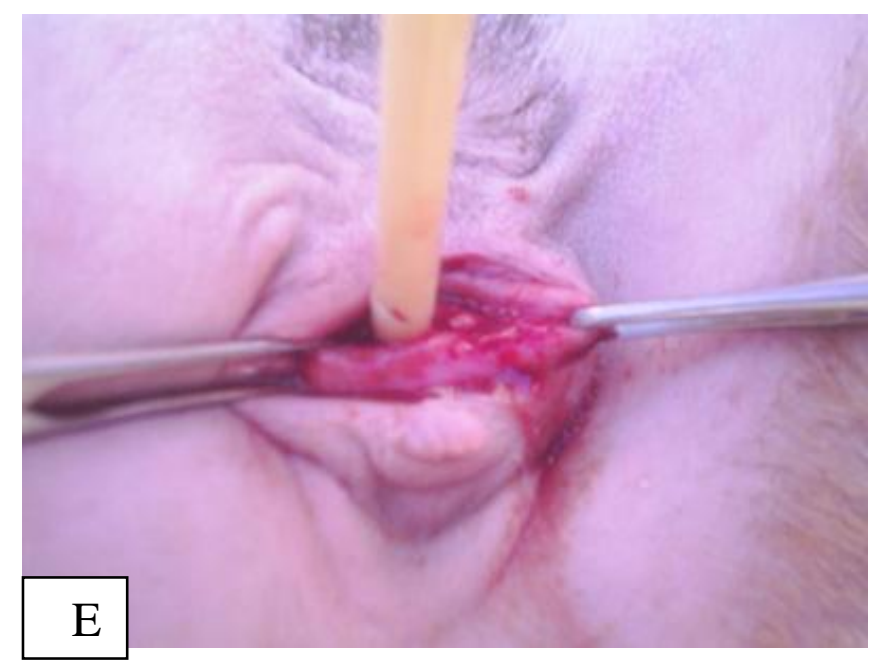

Fig. 5. The transcervical technique, A- Immobilization of ewes in a standing position, B- A lubricated speculum inserted into the vagina, $C$ - The external os of the cervix was grasped with the Allis forceps and pulled to vulval opening, D- A bovine teat dilator introduced into cervical canal and gradually dilated in order to dilate and open the cervical canal with a help of screw provided with the instrument, E- A three-way Foley catheter was introduced, and gentile probing and twisting motion passed the cervical canal with the aid of a stylet.

\section{References}

1- Cognie Y. 1999. State of art in sheepgoat embryo transfer. Theriogenology, 51: 105-116.

2- Gusmão, A. L., Silva J. C., Bittencourt T. C. C., Martins L. E. P., Gordiano H. D. , Barbosa L. P. 2009. Transcervical embryo recovery in Dorper ewes in the Brazilian semi-arid Northeast. Arq. Bras. Med. Vet. Zootec., 61: 313-318.

3- Halbert G. W., Dobson H., Walton J. S., Buckrell B. C. 1990. The structure of the cervical canal of the ewe. Theriogenology, 33: 977-902.

4- Andersen, V. K., Aamdal J., Fougner J. A. 1973. Intrauterine and deep cervical insemination with frozen semen in sheep. Zuchthygiene (Berlin) 8:113-118.

5- Bunch, T. D., H. S. Ellsworth. 1981. Gross anatomy of the ovine cervix. Int. Goat Sheep Res. 1:282-285.

6- Kraemer D. C. 1989. Embryo collection and transfer in small ruminants. Theriogenology, 31:141-148.
7- Wulster-Radcliffe M. C., Wang S., Lewis G.S. 2004. Transcervical artificial insemination in sheep: effects of a new transcervical artificial insemination instrument and traversing the cervix on pregnancy and lambing rates. Theriogenology, 62: 990-1002.

8- Mylne M. J., McKelvey W. A., Fernie K., Matthews K. 1992. Use of a transcervical technique for embryo recovery in sheep. Vet. Rec., 130: 450-451.

9- Pereira R. J. T. A., Sohnrey B., Holtz W. 1998. Nonsurgical embryo collection in goats treated with prostaglandin F2 $\alpha$ and oxytocin. J. Anim. Sci., 76: 360-363.

10- Khalifa R. M., Sayre B. L., Lewis G.S. 1992. Exogenous oxytocin dilates the cervix in ewes. J. Anim. Sci., 70: $38-42$.

11-Wulster-Radcliffe M. C., Costine B. A., Lewis G.S. 1999. Estradiol17 beta-oxytocin-induced cervical dilation in sheep: application to transcervical 
embryo transfer. J. Anim. Sci., 77: 2587-2593.

12-Stellflug J. N., Wulster-Radcliffe M. C., Hensley E. L., Cowardin E. A., Seals R. C., Lewis G.S. 2001. Oxytocin-induced cervical dilation and cervical manipulation in sheep: effects on laparoscopic artificial insemination. J Anim Sci, 79: 568-573.

13-Bari F., Khalid M., Haresign W., Murray A., Merrell B. 2000. Effect of mating system flushing procedure, progesterone, dose and donor ewe age on the yield and quality of embryos within MOET program in sheep. Theriogenology, 53: 727-742.

14- McKelvey, W.A.C., Robinson, J.J., Aitken, R.P., Robertson, I.S., 1986. Repeated recoveries of embryos from ewes by laparoscopy. Theriogenology 25 , 855-865.

15-Campbell J. W., Harvey T. G., McDonald M, F., Sparksman R. I. $\quad$ 1996. Transcervical insemination in sheep: an anatomical and histological evaluation. Theriogenology, 45: 1535-1544. 


\title{
تقتية حديثة لاستخلاص الأجنة في النعاج المعاملة بفرط الاباضة باستعمال

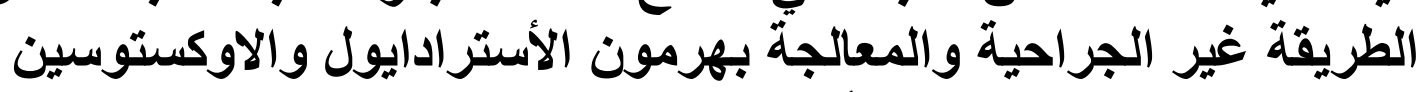

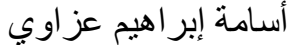 \\ كلية الطب البيطري/ جامعة الموصل إيز \\ الخلاصة
}

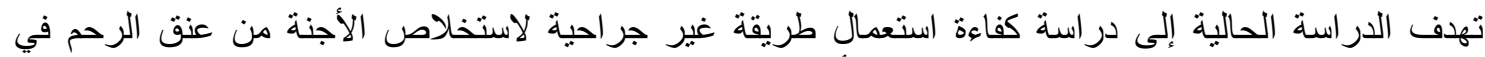

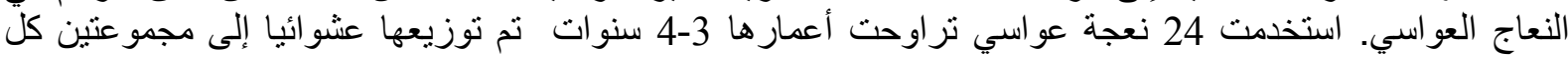

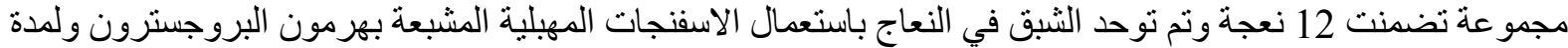

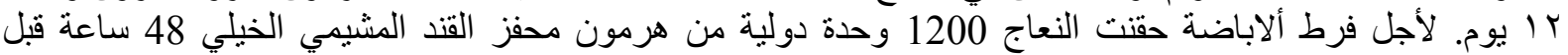

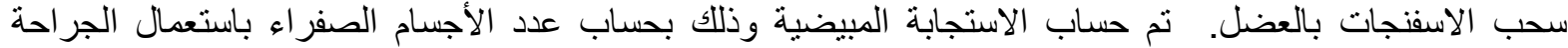

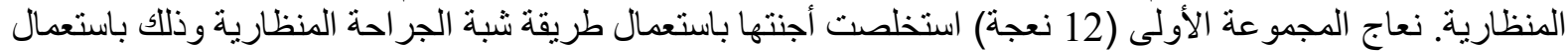

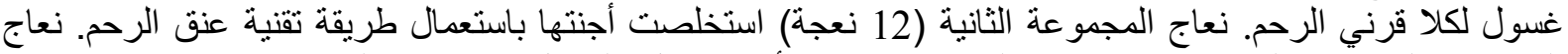

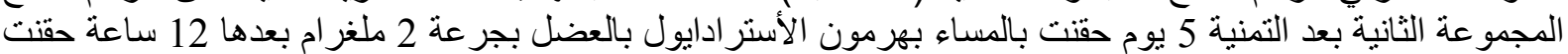

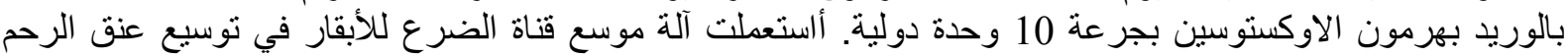

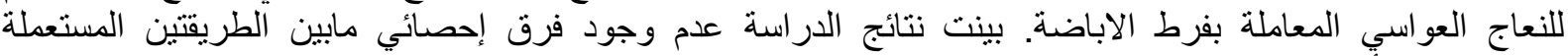

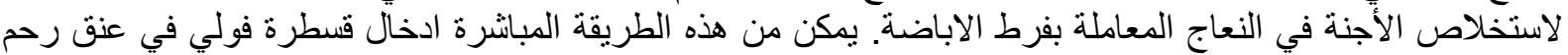

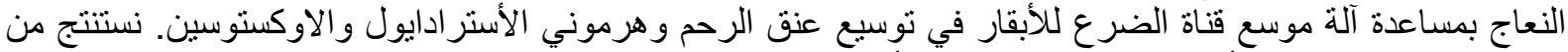

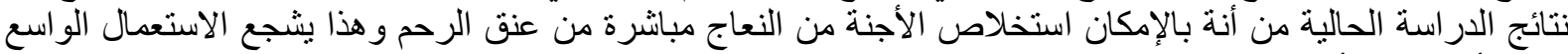

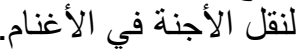

